\title{
Rancang Bangun Robot Omni untuk Mencari Sumber Gas Menggunakan Kontrol Logika Fuzzy Berbasis Mikrokontroler ARM STM-32
}

\author{
Azhar Dwi Rizqi Aljabar, Muhammad Rivai, Suwito \\ Departemen Teknik Elektro, Fakultas Teknologi Elektro, Institut Teknologi Sepuluh Nopember \\ E-mail: azhar.rizqi12@gmail.com,muhammad_rivai@ee.its.ac.id,masaji@ee.its.ac.id
}

\begin{abstract}
Abstrak-Kebocoran gas yang tidak terdeteksi dapat menyebabkan bahaya yang dapat mengancam penggunanya, seperti tejadinya kebakaran, atau meledaknya sebuah tabung gas. Untuk itu dibutuhkan sebuah metode penanganan cepat untuk mengetahui letak terjadinya kebocoran gas. Pada penelitian ini telah dirancang dan dibuat suatu Omni Directional Wheels Robot yang berfungsi sebagai gas tracker untuk mendeteksi letak kebocoran gas. Rancang bangun gas tracker ini menggunakan platform lingkaran yang dilengkapi dengan tiga buah sensor gas semikonduktor MQ-4, yang ditempatkan pada tiap $120^{\circ}$ sudut platform robot. Robot ini menggunakan sistem fuzzy logic controller yang diolah menggunakan STM32F4-Discovery. Robot ini akan mencari sumber kebocoran gas dengan menggunakan hasil pendeteksian dari sensor gas. Input fuzzy logic berupa perubahan nilai tegangan sensor gas. Pada proses defuzzifikasi dihasilkan output berupa sudut datang dan jarak sumber gas terhadap robot. Hasil deffuzifikasi kemudian akan berfungsi sebagai input gerak robot sesuai dengan perhitungan kinematika robot. Dari hasil pengujian menunjukkan bahwa robot ini dapat menuju ke sumber gas dengan nilai rata-rata tertinggi adalah $93,33 \%$ saat sudut $210^{\circ}$.
\end{abstract}

Kata Kunci-Fuzzy Logic Controller, Omni Directional Wheels Robot, Sensor gas semikonduktor.

\section{PENDAHULUAN}

$S_{k+1}^{A}$ ALAH satu resiko penggunaan LPG adalah terjadinya kebocoran gas yang dapat menyebabkan kebakaran jika terpicu oleh api yang berada di sekitarnya. Dalam industri atau instalasi gas, pipa merupakan aspek penting untuk mendistribusikan gas dari suatu tempat ke tempat yang lain. Kebocoran pada pipa yang tidak terdeteksi dapat menyebabkan kerusakan lebih parah dan dapat mengakibatkan kerugian yang sangat besar karena proses produksi berhenti.

Dalam penelitian ini telah dibuat rancang bangun Robot Omni yang dilengkapi dengan sensor gas MQ-4 dan sensor jarak HC-SR04. Robot Omni berfungsi untuk mencari sumber gas untuk mendeteksi letak awal kebocoran gas. Dengan menggunakan metode fuzzy logic controller, robot akan mencari sumber kebocoran gas. Robot dilengkapi dengan sensor jarak yang berfungsi untuk mendeteksi halangan yang ada pada sekitar sumber kebocoran gas, sehingga kebocoran dapat dideteksi secara dini dan dapat mencegah kerusakan lebih lanjut.

\section{TINJAUAN PUSTAKA}

\section{A. Omni Directional Wheels}

Roda omni (omni wheels) adalah rancangan roda khusus yang tidak hanya mempunyai roda tunggal, tetapi banyak roda dalam satu roda inti. Ada roda inti besar, dan sepanjang tepi ada banyak roda kecil tambahan yang mempunyai sumbu tegak lurus terhadap sumbu roda inti. Roda omni-directional holonomic memiliki 3 DOF. Berbeda dengan robot nonholonomic normal, robot omni-directional holonomic mampu bergerak ke segala arah tanpa mengubah arah roda [1]. Robot omni dapat bergerak maju, mundur, geser kesamping, dan berputar pada posisi tetap. Kemampuan ini memungkinkan robot yang menggunakan omnidirectional mampu bermanuver lebih lincah dan lebih efisien.

Berdasarkan sifatnya, omni directional wheels adalah jenis mobile robot holonomic. Robot ini dapat bertranslasi ke arah kiri maupun kanan tanpa terlebih dahulu mengubah orientasi robot atau arah robot. Oleh karena itu dapat dikatakan bahwa kinematik sebuah roda omni adalah untuk memberi sarana dalam merubah posisi antar kordinat global dan konfigurasi internal, ditunjukkan pada Gambar 1.
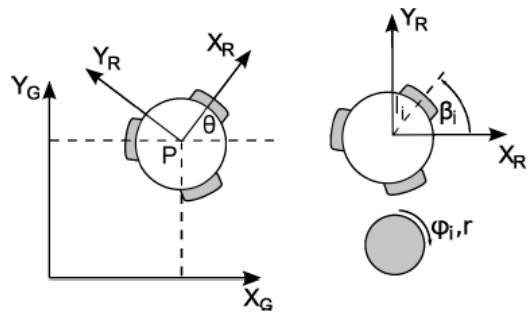

Gambar 1. Sistem kinematik Omni Directional Wheels Robot [1]

\section{B. Sensor gas $M Q-4$}

Sensor gas dengan kode MQ terdiri dari 2 bagian, yaitu sensor elektrokimia dan sebuah pemanas internal di dalamnya, ditunjukkan pada Gambar 2. Sensor ini dapat mendeteksi berbagai tipe gas, dan akan lebih sensitif untuk jenis gas tertentu. Semua sensor gas tipe ini harus dikalibrasi dengan mengukurnya pada udara/gas yang telah diketahui konsentrasinya. Keluaran sensor ini berupa data analog yang dapat dibaca oleh pin-pin analog mikrokontroller [2]. 


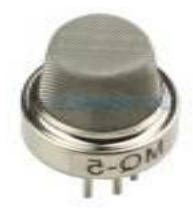

Gambar 2. Sensor gas MQ [2]

Sensor gas MQ merupakan sensor gas yang terbuat dari keramik mikro $\mathrm{AL}_{2} \mathrm{O}_{3}$, Tin Dioxide $\left(\mathrm{SnO}_{2}\right)$ yang sensitif, elektroda dan kepala sensornya terbuat dari plastic serta stainless steel . Kepala sensornya dapat bekerja dengan baik dan merupakan komponen yang sangat sensitive [2].

\section{Sensor Jarak HC-SR04}

Modul sensor HC-SR04 merupakan sensor yang banyak digunakan untuk mengukur jarak suatu objek, ditunjukkan pada Gambar 3. Jarak jangkauan yang dimiliki oleh sensor ini yaitu mulai dari sekitar 2 centimeter sampai 4 meter. Dengan jangkauan yang cukup jauh tersebut dan ketelitian hingga sekitar 1 centimeter menjadikan modul sensor ini sering digunakan pada berbagai aplikasi, mulai dari pengukur ketinggian air hingga pengukur jarak pada berbagai robot.

Sensor ini bekerja dengan memanfaatkan gelombang ultrasonik. Dengan menggunakan prinsip kerja layaknya suatu perangkat sonar, yaitu dengan memanfaatkan pantulan gelombang ultrasonik dan mengukur waktu penerimaan pantulannya, maka dapat didapatkan nilai jarak antara sensor ini dengan objek yang ingin diukur jaraknya. Frekuensi ultrasonik yang dipakai sensor ini sebesar $40 \mathrm{kHz}$ [3].

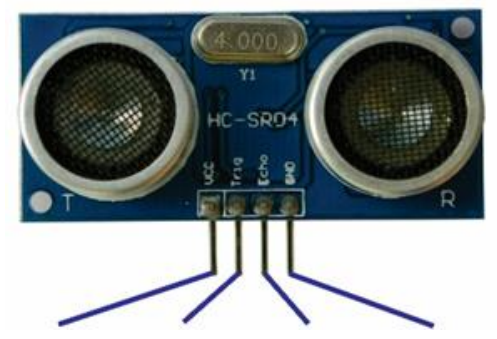

Gambar 3. Sensor Jarak HC-SR04 [3]

\section{PERANCANGAN SISTEM}

Perancangan sistem pada gas tracker robot yang akan dirancang terdiri dari dua bagian besar, yaitu perancangan perangkat keras dan perangkat lunak. Pada perancangan perangkat keras terdiri atas, perancangan mekanik robot omni, perancangan elektrik, dan perancangan sensor gas dan jarak. Perancangan perangkat keras tersebut berfungsi sebagai platform dasar mobile gas tracker yang akan dirancang menggunakan sistem gerak robot omni untuk mencari gas bocor. Sensor gas yang digunakan merupakan sensor gas MQ4. Sensor ini adalah sebuah sensor gas yang meliputi gas metana, karbondioksida, isobutana, ethanol, dan hydrogen. Sedangkan sensor jarak yang digunakan adalah modul sensor HC-SR04 yang memanfaatkan gelombang ultrasonik untuk mendeteksi jarak yang ada di depannya. Untuk perancangan perangkat lunak meliputi program pada STM32F4 dan kendali
Fuzzy Logic. Semua perancangan sistem perangkat lunak berfungsi untuk sistem kontrol pada mobile robot.

\section{A. Desain Mekanik Robot Omni}

Tahapan desain sebuah robot adalah merancang robot dengan kelengkapan serta ukuran yang di skalakan. Pada penelitian ini mendesain badan utama dari omni wheels robot yang bertipe holonomic, ditunjukkan pada Gambar 4.

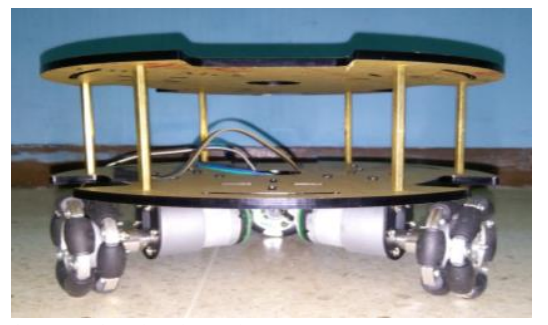

Gambar 4. Desain Omni Wheels Robot

Setelah mendesaian model badan robot, implementasi dari badan robot berdasarkan desain yang dibuat terdiri atas:

- Rangka robot : akriklik dan aluminium

- Roda : roda omni wheel aluminium dan karet

- Penggerak roda : Motor DC 12V

\section{B. Rangkaian Sensor Gas}

Rangkaian sensor gas yang digunakan pada penelitian ini adalah rangkaian pengondisi tegangan output dari sensor MQ4. Rangkaian pembagi tegangan diperlukan untuk mengambil Vout dari sensor, ditunjukkan pada Gambar 5. Ketika sensor gas mendeteksi adanya gas pada udara, maka resistansi dalam sensor gas akan turun begitu pula sebaliknya.
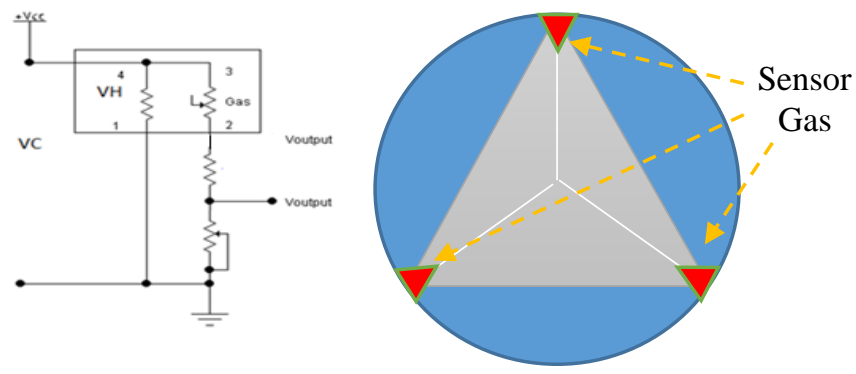

Gambar 5. Rangkaian dasar sensor gas dan penempatan sensor

Sensor gas MQ membutuhkan dua sumber tegangan yaitu tegangan rangkaian $(\mathrm{Vc})$ dan tegangan pemanas (Vh). Sedangkan output dari nilai sensor dilihat pada tegangan output pada rangkaian pembagi tegangan. Resistor yang digunakan untuk pembagi tegangan masin-masing $10 \mathrm{~K}$ sehingga nilai maksimum tegangan yang masuk ke STM32F4 memiliki nilai maksimum 3.3 Volt. Output dari tegangan sensor gas dimasukkan kedalam pin ADC pada mikrokontroller.

\section{Rangkaian Sensor Jarak}

Modul HC-SR04 membutuhkan tegangan 5 volt, sedangkan mikrokontroller STM32F4 hanya mampu mengeluarkan tegangan output sebesar 3.3 volt. Untuk mengatasi masalah ini 
diperlukan perencanaan rangkaian tambahan untuk mengoperasikan HC-SR04 dengan baik [2]. STM32F4 menyediakan 5-tolerant pin yang mampu di-drive oleh tegangan luar sebesar 5 volt apabila pin output diset sebagai Open Drain dengan memberikan pull-up 5 volt menggunakan resistor $1 \mathrm{Kohm}$. Sedangkan untuk mengatasi kebutuhan pin echo HC-SR04 yang mengeluarkan tegangan 5 volt sebagai indikator pembacaan sinyal ultrasonik, tegangan pin echo dapat disambungkan dengan rangkaian pembagian tegangan sebelum disambungkan dengan pin input STM32F4, ditunjukkan pada Gambar 6.

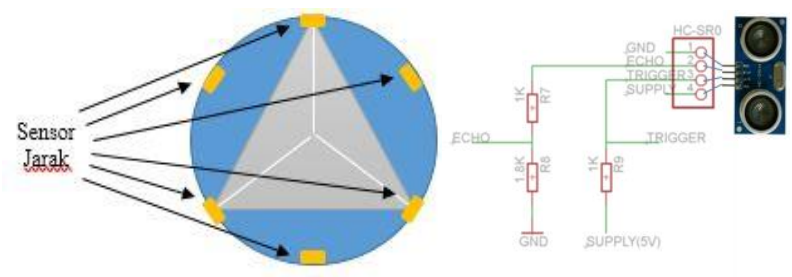

Gambar 6. Rangkaian dasar sensor jarak dan penempatan sensor

\section{Perancangn Sitem Kontrol Robot}

Penelitian ini menggunakan fuzzy logic control sebagai sistem kontrol yang akan mengatur sistem utama pada pergerakan kinematik omni directional wheels. Fuzzy logic digunakan untuk menggerakan roda omni berdasarkan input data yang diterima sensor gas MQ-4 yang telah diolah pada STM32F4. Data input dari sensor tersebut akan menunjukan posisi dari kebocoran gas yang terjadi. Pergerakan roda menggunakan fuzzy logic yang akan mengatur pergerakan tiga buah motor dengan input dari tiga buah sensor gas MQ-4. Pergerakan roda omni sendiri didefinisikan berdasarkan jarak gas terhadap robot yang diambil berdasarkan nilai ADC yang diterima oleh sensor gas MQ-4.

Berdasarkan nilai ADC yang diterima maka akan diketahui sudut datangnya gas yang menjadi output fuzzy sebagai panduan pergerakan robot omni, ditunjukkan pada Gambar 7 . Hasil dari pembacaan nilai ADC tersebut akan menjadi membership function untuk alur pergerakan robot. Jadi pada setiap motor akan memiliki 3 buah inputan hasil pembacaan ADC masing masing sensor gas MQ-4 yang berupa posisi sumber gas berdasarkan sudut datang dan jarak sumber tersebut dari titik sensor.

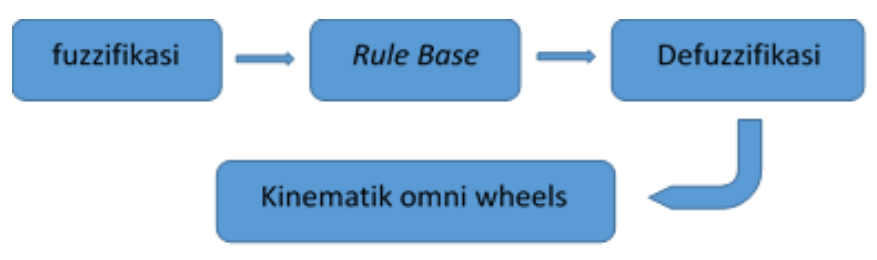

Gambar 7. Alur sistem Fuzzy Control

\section{a. Fuzzifikasi}

Pada sistem ini menggunakan crisp input yang dibentuk dari lima himpunan keanggotaan (ditunjukkan pada Gambar 8) yang menggambarkan jarak datangnya sumber sensor yaitu:

a. None (tidak terdeteksi adanya sumber gas)

b. Long (sumber gas jauh dari jangkauan sensor) c. Medium (sumber gas medium dari jangkauan sensor)

d. Short (sumber gas dekat dari jangkauan sensor)

e. Stop (sumber gas berada pada threshold nilai sensor)

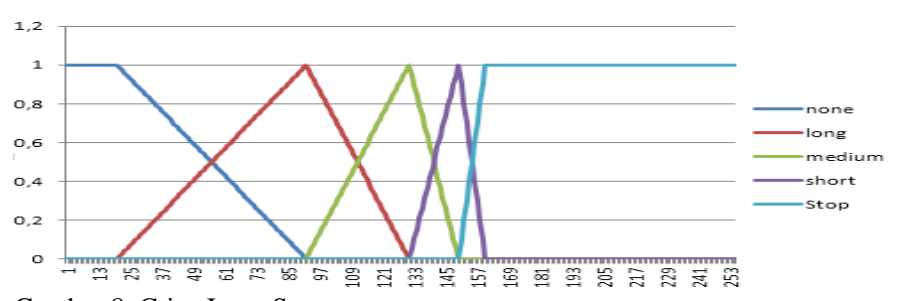

Gambar 8. Crisp Input Sensor

\section{b. Fuzzy Rule Base}

Fuzzy Rule Base yang diatur pada sistem ini diolah berdasarkan sudut datang dan jarak sumber gas terhadap robot omni. Tiap fungsi keanggotaan bertipe singleton. Untuk penentuan sudut datang sumber gas dibedakan menjadi enam kuadran, ditunjukkan pada Tabel 1.

Tabel 1.

Keanggotaan Sudut

\begin{tabular}{cc}
\hline \hline Keanggotaan & Tipe keanggotaan \\
\hline $30^{\circ}$ & Singleton \\
$90^{\circ}$ & Singleton \\
$150^{\circ}$ & Singleton \\
$210^{\circ}$ & Singleton \\
$270^{\circ}$ & Singleton \\
$330^{\circ}$ & Singleton \\
\hline \hline
\end{tabular}

Sedangkan jarak tangkap atau magnitude ditentukan menurut input yang didapat dari pembacaan jarak $(\mathrm{cm})$ pada tiap sensor yang terbagi kedalam empat derajat keanggotaan stop, short, medium, long, ditunjukkan pada Tabel 2.

Tabel 2.

Keanggotaan Jarak

\begin{tabular}{ccc}
\hline \hline $\begin{array}{c}\text { Keanggotaan } \\
\text { jarak }(\mathrm{cm})\end{array}$ & $\begin{array}{c}\text { Kategori } \\
\text { keanggotaan }\end{array}$ & $\begin{array}{c}\text { Tipe } \\
\text { keanggotaan }\end{array}$ \\
\hline 10 & Stop & Singleton \\
20 & Dekat & Singleton \\
30 & Medium & Singleton \\
40 & Jauh & Singleton \\
\hline \hline
\end{tabular}

\section{c. Defuzzifikasi}

Fuzzy kontrol yang digunakan pada sistem ini menghasilkan dua buah output yaitu derajat keanggotaan sudut berdasarkan kuadran sudut dan jarak, sehingga dapat mengarahkan keputusan pergerakan kinematik robot, ditunjukkan ada Gambar 9 dan 10. 


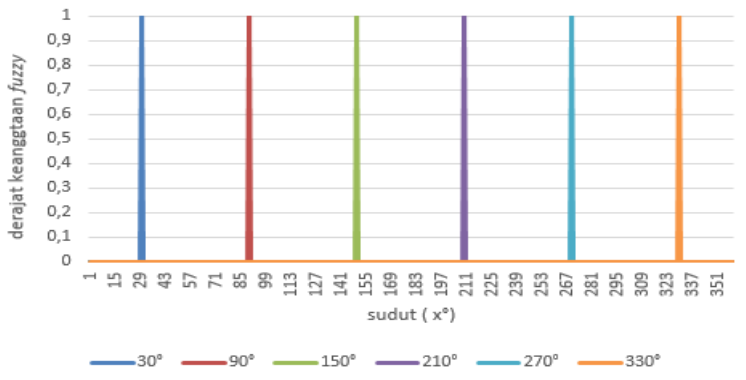

Gambar 9. Crisp Output Sudut

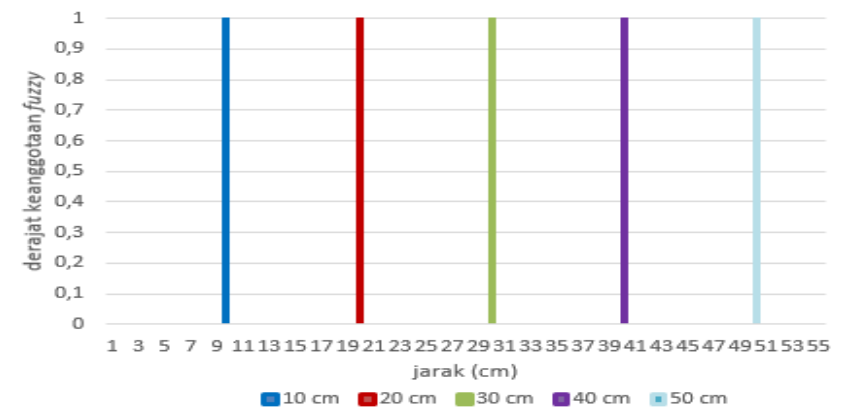

Gambar 10. Crisp Output Jarak

Defuzzifikasi pada sistem ini menggunakan metode Max Product Implication Methode. Metode ini memungkinkan pengambilan nilai maksimum keluaran dari crisp output sudut dan jarak sebagai keputusan akhir dari proses fuzzy yang telah direncanakan menggunakan Fuzzy Rule Base. Hasil defuzzifikasi berupa sudut dan jarak akan menjadi input dari kinematik robot omni. Dengan mengetahui jarak (S) dan sudut maka akan dapat menghitung magnitude $(\mathrm{M})$ yang merupakan besarnya skala pergerakan dalam kuadran kartesian $(\mathrm{x}, \mathrm{y}, \varphi)$ yang akan menjadi input kinematik robot omni, dengan rumusan sebagai berikut:

$M=\left\{\frac{\operatorname{Mmax}-M \min }{\operatorname{Smax}-\operatorname{Smin}} *(s-\operatorname{smin})\right\}+M \min$

Keterangan :

$$
\begin{aligned}
\text { Mmax } & =250 \text { (PWMmax) } \\
\text { Mmin } & =150 \text { (PWMmin) } \\
\text { Smax } & =40 \mathrm{~cm} \text { (long) } \\
\text { Smin } & =10 \mathrm{~cm} \text { (Short) }
\end{aligned}
$$

\section{HASIL DAN ANALISA}

Setelah melakukan perancangan mekanik berdasarkan desain robot, maka implmentasi dari desain omni directional wheels pada penelitian ini dapat dilihat pada Gambar 11 . Tabel 3 menunjukkan pengujian sensor gas MQ-4.

Pada gambar 12 menunjukkan bahwa semakin jauh jarak sumber gas maka tingkat sensitifitas sensor gas semakin berkurang. Hal ini disebabkan oleh kemampuan identifikasi sensor terhadap gas alokohol.

Untuk mendapatkan nilai yang akurat, pengambilan data nilai ADC dilakukan dalam waktu 5 menit dengan membagi derajat keanggotaan nilai ADC ditunjukkan pada Tabel 4, dengan rincian sebagai berikut:
a. None $=$ tidak ada sumber gas
b. Long $=$ sumber berjarak $40 \mathrm{~cm}$

c. Medium $=$ sumber berjarak $30 \mathrm{~cm}$

d. Short $=$ sumber berjarak $20 \mathrm{~cm}$

e. Stop $=$ sumber berjarak $10 \mathrm{~cm}$

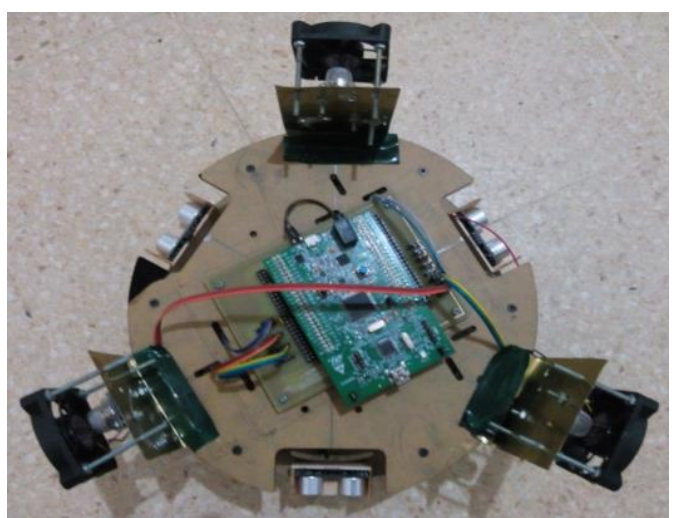

Gambar 11. Realisasi Robot Omni

Tabel 3.

Data Pengukuran Tegangan Sensor Gas MQ percobaan 1

\begin{tabular}{cccc}
\hline sensor 1 & sensor 2 & sensor 3 & Jarak $(\mathrm{cm})$ \\
\hline 1.18 & 0.94 & 1.07 & 20 \\
1.06 & 0.83 & 1.03 & 40 \\
1.04 & 0.76 & 0.99 & 60 \\
\hline \hline
\end{tabular}

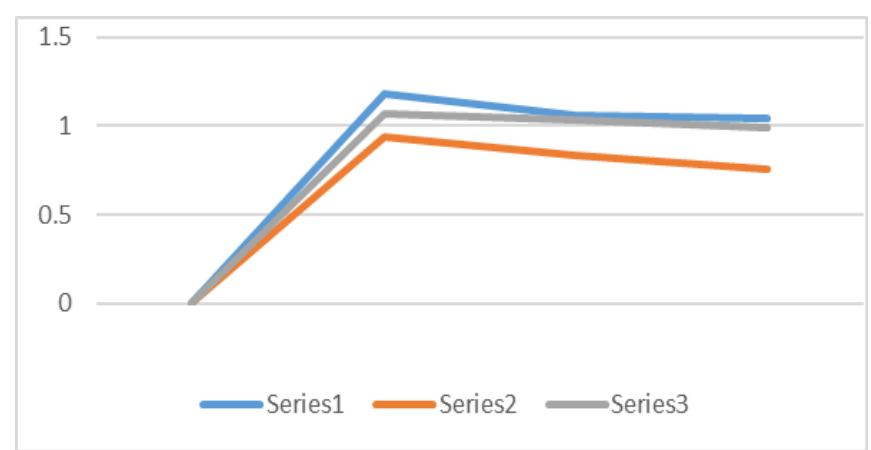

Gambar 12. Grafik Tegangan Sensor Dalam Range 0-60 cm

Tabel 4.

Pembacaan ADC sensor

\begin{tabular}{llllll}
\hline \hline \multicolumn{7}{c}{ Pembacaan ADC sensor } \\
\hline & none & Long & Medium & Short & Stop \\
\hline Sensor 1 & 20 & 92 & 131 & 150 & 160 \\
Sensor 2 & 15 & 82 & 121 & 140 & 150 \\
Sensor 3 & 18 & 86 & 125 & 142 & 157 \\
\hline \hline
\end{tabular}

Pada Gambar 13 menunjukkan pengujian sensor HC-SR04 terhadap jarak dinding pantulan. Pengujian dilakukan dengan jarak antara sensor dengan dinding pantulan yang berbedabeda, ditunjukkan pada Tabel 5. Dapat dilihat bahwa pengukuran sensor semakin tidak sesuai seiring dengan pertambahan jarak antara sensor dengan dinding pantul. 


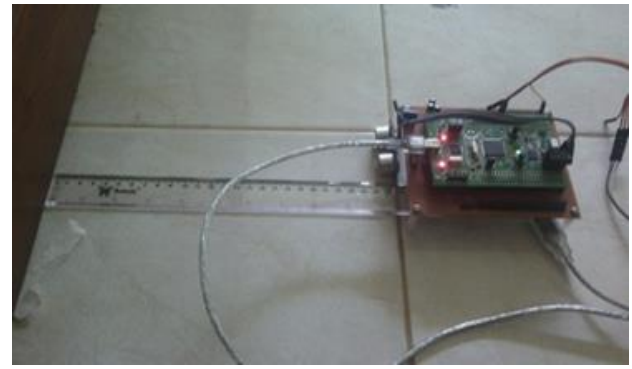

Gambar 13. Pengujian Sensor jarak

Pengujian Fuzzy Logic pada sistem dilakukan untuk menguji hasil dari sistem yang telah dirancang pada robot. Pada pengujian ini dilakukan percobaan untuk melihat perbandingan hasil input dan output pada robot. Pengujian dilakukan berdasarkan jarak sumber gas $(10 \mathrm{~cm}, 20 \mathrm{~cm}, 30 \mathrm{~cm}, 60 \mathrm{~cm})$ antara tiap sensor dan sudut datang $\left(30^{\varpi}, 90^{\varpi}, 150^{\varpi}, 210^{\varpi}, 270^{\varpi}, 330^{\varpi}\right)$.

Tabel 5.

Pengujian Sensor Jarak

\begin{tabular}{cccc}
\hline \hline Jarak $(\mathrm{cm})$ & Hasil Pembacaan & $\begin{array}{c}\text { Error } \\
\text { (Selisih jarak) }\end{array}$ & $\begin{array}{c}\text { Persentase } \\
\text { kesalahan }\end{array}$ \\
\hline 5 & 5.060741 & 0.060741 & 1.21482 \\
10 & 10.121482 & 0.121482 & 1.21482 \\
15 & 15.814816 & 0.814816 & 5.43211 \\
20 & 20.242964 & 0.242964 & 1.21482 \\
25 & 25.303705 & 0.303705 & 1.21482 \\
30 & 31.629631 & 1.629631 & 5.43210 \\
35 & 36.690372 & 1.690372 & 4.82963 \\
40 & 41.751114 & 1.751114 & 4.37779 \\
45 & 47.444447 & 2.444447 & 5.43210 \\
50 & 52.505188 & 2.505188 & 5.01038 \\
55 & 58.198521 & 3.198521 & 5.81549 \\
60 & 63.891853 & 3.891853 & 6.48642 \\
\hline \hline
\end{tabular}

Berikut ini merupakan hasil pengujian terhadap fuzzy control yang berupa hasil deteksi sensor dan pergerakan robot dalan kordinat $(x, y, \varphi)$.

a. Sumber gas $90^{\circ}$ pada $30 \mathrm{~cm}$

Tabel 6 .

\begin{tabular}{ccc}
\multicolumn{3}{c}{ Tabel 6.} \\
\multicolumn{3}{c}{ Pembacaan tegangan sensor sumber gas $90^{\circ}$} \\
\hline Sensor1 & Sensor2 & Sonsor3 \\
\hline $1.473 \mathrm{~V}$ & $1.343 \mathrm{~V}$ & $1.35 \mathrm{~V}$ \\
\hline \hline
\end{tabular}

Sesuai dengan defuzzifikasi maka robot bergerak pada kordinat $\left(x_{v} y_{v} \varphi\right)=(0,216,6,0)$

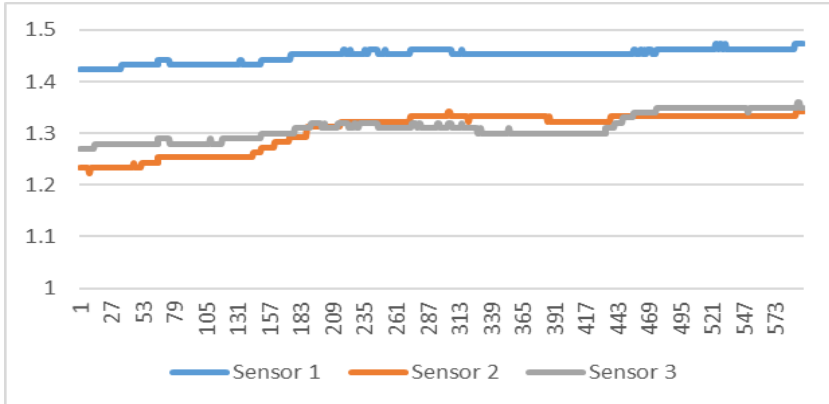

Gambar 14. Grafik kondisi sensor Sumber gas $210^{\circ}$ pada $20 \mathrm{~cm}$

b. Sumber gas $210^{\circ}$ pada $30 \mathrm{~cm}$

Tabel 7.

Pembacaan tegangan sensor sumber gas $210^{\circ}$

\begin{tabular}{ccc}
\hline \hline Sensor1 & Sensor2 & Sensor3 \\
\hline $1.223 \mathrm{~V}$ & $1.4 \mathrm{~V}$ & $1.21 \mathrm{~V}$ \\
\hline
\end{tabular}

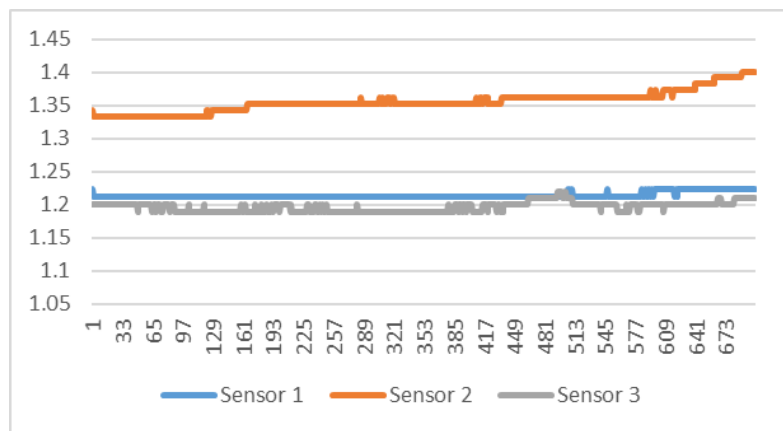

Gambar 15. Grafik kondisi sensor Sumber gas $330^{\circ}$ pada $20 \mathrm{~cm}$

Sesuai dengan defuzzifikasi maka diambil keputusan :

Output Sudut $=210^{\circ}$

Output Jarak $=30 \mathrm{~cm}$ (medium)

Maka $\mathrm{M}=216,6$

$$
\begin{aligned}
x & =216,6 \cos 210^{\circ} \\
& =-187,57 \\
y & =216,6 \sin 210^{\circ} \\
& =-108,3
\end{aligned}
$$

Robot bergerak pada kordinat $(x, y, \varphi)=(-187,57,-108,3,0)$

c. Sumber gas $330^{\circ}$ pada $30 \mathrm{~cm}$

Tabel 8.

Pembacaan tegangan sensor sumber gas $330^{\circ}$ pada $30 \mathrm{~cm}$

\begin{tabular}{ccc}
\hline \hline Sensor1 & Sensor2 & Sonsor3 \\
\hline $1.513 \mathrm{~V}$ & $1.563 \mathrm{~V}$ & $1.62 \mathrm{~V}$ \\
\hline \hline
\end{tabular}

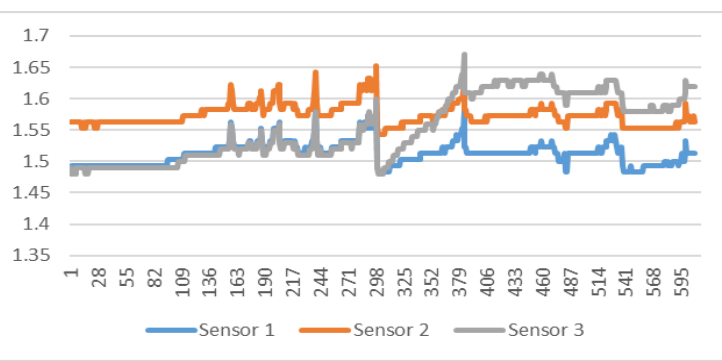

Gambar 16. Grafik kondisi sensor Sumber gas $330^{\circ}$ pada $30 \mathrm{~cm}$ 
Sesuai dengan defuzzifikasi maka robot bergerak pada kordinat $\left(x_{v} y, \varphi\right)=(187,57,-108,3,0)$

\section{KESIMPULAN}

Pada penelitian ini telah dirancang sebuah platform robot Omni Directional Wheels yang berfungsi sebagai gas tracker. Robot ini menggunakan tiga buah sensor gas MQ-4 untuk mendeteksi gas, sensor jarak ultrasonik HC-SR04 untuk mendeteksi adanya obstacle dan Fuzzy Logic sebagai kontrol sistem dari robot. Robot ini menggunakan mikrokontroler ARM STM32F4 untuk mengatur keseluruhan sitem robot beserta pengaturan perangkat mekanik dan elektrik pada robot. Rancang bangun robot omni ini menggunakan input fuzzifikasi pembacaan sensor gas dan deffuzifikasi yang berupa sudut datangnya gas terhadap titik pusat robot dan jarak sumber gas dari robot. Keluaran kontrol logika fuzzy tersebut menjadi masukan untuk perhitungan besarnya pergerakan robot dalam kuadran kartesian. Hasil percobaan menunjukkan bahwa sensor gas dapat mendeteksi gas alkohol dengan kondisi ideal membutuhkan jarak di bawah $50 \mathrm{~cm}$ dan dalam waktu 5 menit dikarenakan terjadi fluktuatif penyemprotan gas yang dilakukan. Tingkat keberhasilan rata-rata tertinggi dalam menemukan sumber gas adalah pada sudut $210^{\circ}$ dengan persentase $93,33 \%$.

\section{DAFTAR PUSTAKA}

[1] T. . Baede, "Motion Control of an Omnidirectional Mobile robot," Eindhoven University of Technology, 2006.

[2] Anonim, "Technical Information for MQ-4 gas sensor," 2017. [Online]. Available: https://www.sparkfun.com/datasheets/Sensors/Biometric/MQ-4.pdf.

[3] H. Maulana, "Implementasi Mikroprosesor Arm Pada Robot Hexapod untuk Melacak Sumber Kebocoran Gas Alkohol," Institut Teknologi Sepuluh Nopember, 2016. 